\title{
Notes for a History of the Teaching of Algebra ${ }^{1}$
}

\author{
João Pedro da Ponte \\ Instituto de Educação da Universidade de Lisboa \\ Henrique Manuel Guimarães \\ Instituto de Educação da Universidade de Lisboa
}

\section{Introduction}

Abundant literature is available on the history of algebra. However, the history of the teaching of algebra is largely unwritten, and as such, this chapter essentially constitutes some notes that are intended to be useful for future research on this subject. As well as the scarcity of the works published on the topic, there is the added difficulty of drawing the line between the teaching of algebra and the teaching of arithmetic-two branches of knowledge whose borders have varied over time (today one can consider the arithmetic with the four operations and their algorithms and properties taught in schools as nothing more than a small chapter of algebra). As such, we will be very brief in talking about the more distant epochs, from which we have some mathematics documents but little information on how they were used in teaching. We aim to be more explicit as we travel forwards into the different epochs until modern times. We finish, naturally, with some reflections on the present-day and future situation regarding the teaching of algebra.

\section{From Antiquity to the Renaissance: The oral tradition in algebra teaching}

In the period from Antiquity to the Renaissance, algebra was transmitted essentially through oral methods. The written records, such as clay tablets and papyri, were used to support oral teaching but duplication was expensive and time-consuming. These artefacts, however, were important for the continuity of memory in the long term.

Mathematics began to be developed through the facets of geometry and arithmetic. However, we also find primitive manifestations of mathematics that we can link to algebra in several epochs and dispersed regions around the world. In Mesopotamia, earlier than $3000 \mathrm{BC}$, records exist of relatively abstract problems, often presented as practical problems. Some Mesopotamian tablets may even be regarded as small textbooks, such as one that lists 21 problems. Whereas traditional accounts (Boyer \& Merzbach 1980) assume that these problems already have an algebraic nature, more recent views suggest that they involved simply calculating with quantities (Hoyrup 2002). As far back as then, there is evidence of institutionalised teaching and the mathematical texts that included exercises and problems for the student to solve and items for the teacher to use (Schubring 2003).

Diophantus of Alexandria (second half of the $3^{\text {rd }}$ century AD) authored one of his most important works, Arithmetic (split into 13 books, of which only 10 are known). It presents a sequence of problems that can be written in the form of equations and are solved using numerical methods. For each problem the author seeks an integer solution, without attempting to study all the possible solutions or drawing up a general theory on the matter. Diophantus used a sophisticated notation with different abbreviations for the

\footnotetext{
${ }^{1}$ Ponte, J. P., \& Guimarães, H. (2014). Notes for a history of the teaching of algebra. In A. Karp \& G. Schubring (Eds.), Handbook on the history of mathematics education (pp. 459-472). New York: Springer. ISBN 978-1-4614-9154-5 DOI 10.1007/978-1-4614-9155-2_22
} 
square of an unknown number, for the cube and so on successively (Boyer \& Merzbach 1989; Hawking 2010).

Al Khwarizmi ( $9^{\text {th }}$ century AD) wrote what can be considered the founding text of algebra (Al-Kitab al mukhtasar hisab al-jabr wa'l-muqabala, Abrégé du calcul par la restauration et la comparaison), dedicated to the solution of $2^{\text {nd }}$ degree equations. The book starts with a very small presentation of the positional principle of the number system and then states that "the numbers which are required in calculating by al-jabr and al-muqābāla are of three kinds, namely, roots, treasures and simple numbers relative neither root nor treasure". The author goes on to solve all six possible combinations of these kinds of numbers-which yield six kinds of equations, presenting the solution methods through the use of examples. In the second part, he presents geometric demonstrations for the different procedures presented (Boyer \& Merzbach 1989). During this epoch in the Islamic Empire, numerous scriptures were hand-written for educational use. According to Schubring (2003), the Islamic civilisation was the first to create an institution destined for large-scale education at a high level: the madrasa. In this school, the teaching was oral; the teacher read the texts aloud, dictating them and giving some explanations. The students had to memorise exactly what had been taught and show that they had written a faithful transcription.

The Renaissance led to the emergence of several different algebras, such as Die Coss in Germany, published in 1524 by Adam Riese (1492-1559), and O Libro de Algebra en Arithmetica Y Geometria in Portugal, published in 1567 by Pedro Nunes (1502-1578). But the most significant event of this period was the solution to $3^{\text {rd }}$ degree equations by Niccolo Tartaglia (ca. 1500-1557) and $4^{\text {th }}$ degree equations by Ludovico Ferrari (1522-1565), in a complicated story that also involved Scipione del Ferro (14651526). Girolamo Cardano (1501-1576) published these results in his Ars Magna (in 1545), a book that follows the style of Al Khwarizmi's examples. For around three centuries, the solution for polynomial equations became the essential problem of mathematics (Boyer \& Merzbach 1989).

The first European universities or "general studies" arose in the $12^{\text {th }}$ century under the aegis of the Catholic Church, with a view to educate jurists and doctors. The preparative studies, administered by the Faculty of Arts, included Trivium (grammar, rhetoric, and logic) and Quadrivium (arithmetic, geometry, music, and astronomy). Mathematics was part of the Quadrivium but it sometimes was not taught; when it was taught, however, there was no significant presence of algebra. Also in this case, the education was oral. The teacher dictated the texts of the chosen book aloud and that was considered the definitive explanation of the subject. The students had to memorise exactly what was taught, asking for clarification from the masters and showing their registers to be absolutely correct. The teaching therefore comprised of reading (lectio) and discussion (disputatio) (Carvalho 1986; Schubring 2003).

In all these civilisations, the teaching was essentially of an oral nature. Written notes played an important role for the preservation of memory, but did not constitute a tool for teaching and learning. Over time, the teaching of the subject through problems gave way to new forms of presentation, through explanations in common language as well as-from the time of François Viète De Fontenay (1540-1603) (In Artem Analyticen Isagoge, 1591) and René Descartes (1596-1650) (La Géométrie)—symbolic language.

Algebra began to constitute a generalisation of the methods of arithmetic, enabling broader classes of problems to be solved, and it also generated its own problems, transforming itself into a theory of solving polynomial equations. Although many geometric problems and sharing legacies had led to its development, its applications to the 
arithmetic of administration and commerce or astronomy did not give rise to interesting new problems. Therefore, algebra was cultivated above all because of its intrinsic value, as pure mathematics.

\section{$17^{\text {th }}$ to $18^{\text {th }}$ centuries: The emergence of the algebra textbooks}

The invention of print (1445) marks an important turning point: commercial arithmetic textbooks soon appeared. They were followed by geometry textbooks and then algebra textbooks, which were used to support education in the universities, colleges, and other educational institutions that were being created, some of them for the purpose of professional training.

In Catholic countries where the Counter-Reformation prevailed, the Society of Jesus, founded in 1534, took on a leading role in education. The Jesuits created colleges ("collège" in France), where there was less emphasis on mathematics, which was only taught in the last year of the college; they adopted parts of Euclid's Elements as textbook in 1552 (Schubring 2005). Hence, algebra was not part of the Jesuit curriculum. Also in Portugal, at the time of D. João III (end of the $16^{\text {th }}$ century), in the Jesuit colleges (and at Coimbra University, which was also run by the Jesuits), arithmetic, geometry, and astronomy were taught, but algebra was not (Teixeira 1923).

Meanwhile, treatises specifically dedicated to algebra-which was understood as the study of polynomial equations_-began to appear. Antoine Arnauld's book (16121694), Nouveaux Élémens de Géometrie ( $1^{\text {st }}$ edition in $1667,2^{\text {nd }}$ edition in 1683$)$, which was used in the "petites écoles" of Port-Royal, began with the study of operations with quantities ("la quantité ou grandeur en general"); in other words, it developed algebra first and only in a later step applied these notions to geometry. This work (published anonymously) represents a revolution in style, using Descartes' algebraic notation. The book was aimed at a broad, non-specific target public. Afterwards, Jean Prestet (16421691) published his Éléments des Mathématiques $\left(1^{\text {st }}\right.$ edition in $1675,2^{\text {nd }}$ edition in 1689), which was totally dedicated to algebra and was used in the colleges of the Oratory Order, whose curriculum was independent of that of the Jesuits. The author considered algebra as the most general field of mathematics and regarded geometry as a simple applied branch. Both books were followed by other textbooks aimed at the university public (Schubring 2005). Alexis Claude Clairaut (1713-1765) published a textbook in 1746, Éléments d'Algébre, elaborated for private teaching. It included the solution of $4^{\text {th }}$ degree equations. The author intended to follow an allegedly "genetic approach" dealing with the matters in the order of invention, which in practice meant following a problemsolving approach. Boyer and Merzbach (1989) indicate that Clairaut was very successful in showing that the introduction of algebraic notation was necessary and inevitable. Meanwhile, the textbooks that followed this approach can be criticised for avoiding the main conceptual difficulties of the matters dealt with (Schubring 2005).

In Germany, Christian Wolff (1679-1754) wrote a multi-volume textbook, Elementa Matheseos, in Latin (between 1710 and 1713) and in German, following Arnauld's style. The first volume had a chapter on algebra. The work was praised by d'Alembert as the best mathematics book for teaching of the time (Schubring 2003). In England, in the $18^{\text {th }}$ century, there were several elementary algebra textbooks. The Elements of Algebra by Nicholas Sauderson (1682-1739) had five editions (between 1740 and 1792). Thomas Simpson (1710-1761) wrote a Treatise of Algebra that had 18 editions ( $1^{\text {st }}$ in 1745 , last in 1809). Maclaurin (1698-1746) also wrote a Treatise of Algebra that had about 12 editions ( $1^{\text {st }}$ in 1748 , last in 1796). These books were essentially composed of rules and examples. According to Boyer and Merzbach (1989), English algebra textbooks of this century illustrated a tendency toward increasing algorithmic emphasis, 
but left considerable uncertainty about the logical foundations. Euler wrote a popular algebra textbook that was published in German and Russian (1770-72), in French (1774), and in other languages including English. These Elements of Algebra are acknowledged as being of excellent didactic quality (Dunham 2000).

In Portugal, the Marquis of Pombal reformed Coimbra University in 1772, which was endowed with a Mathematics Faculty with four consecrated subjects: algebra and infinitesimal calculus, geometry, mechanics, and astronomy. For the algebra course, a translation (by Monteiro da Rocha) of Elements d'Analyse Mathematique by Etienne Bézout (1739-1783) (1774, 1793, 1801 and 1818 editions) was used (Teixeira, 1923).

As in the universities, mathematics also began to be taught in the military schools that arose in France during the $18^{\text {th }}$ century to educate the officers of the most powerful army of the epoch. The so-called Artillery and Fortification Schools, created in 1720, had strong mathematics education. As such, the Frenchman Bernard Forest de Belidor (1697/8-1761), a teacher in these schools, published the Nouveau Cours de Mathematique (a book containing 656 pages with many diagrams, which had two editions, in 1725 and 1757). It was basically a geometry book applied to artillery and fortifications, but included elements of algebra when necessary. In Portugal, Belidor's book, translated by Manuel de Sousa, was adopted for more than 20 years (1764-1786) in military courses, up until these courses were reassigned to Coimbra University and to the Royal Navy Academy in Lisbon (Valente 1999). The first chapter of Belidor's book contains an introduction to geometry and the second chapter deals with ratios, proportions, sequences, logarithms, and $1^{\text {st }}$ and $2^{\text {nd }}$ degree equations. Chapter 9 deals with conical sections (see Valente 1999, pp. 70-71; algebra does not play an important role in the other chapters). Meanwhile another Frenchman, Etienne Bézout (1739-1783), published his Cours de Mathématiques from 1770 in two series: one with five volumes for the students to become navy officers, and one with four volumes for future artillery officers. In the navy series, the third volume was dedicated to algebra and its application to geometry, while in the artillery series it was the second volume.

According to Valente (1999), Belidor and Bézout's books were complete elementary mathematics courses, where the authors sought to compile updated knowledge of this science with potential interest for the military preparation courses they were destined for. Bézout's textbooks, however, continued to be used after the French Revolution in general education. In Portugal in 1796, at the Lisbon Royal Academy of Coast Guards (aimed at 14 to 18 year olds and later to children from 12 years upwards), the second year was dedicated to algebra, following Bézout's book (Valente 1999, p. 91). At Coimbra University, algebra was taught in the second year, dealing with topics such as literal calculus, analysis, sequences, conical sections, infinitesimal algebra, and differential and integral calculus (Carvalho 1986). Bézout's books were used until the end of the $19^{\text {th }}$ century in secondary schools and colleges all around Europe, the USA, and Brazil.

The $16^{\text {th }}, 17^{\text {th }}$ and $18^{\text {th }}$ centuries witnessed significant changes in education, with printed textbooks playing an increasingly important role in pushing the traditional practice of reading texts aloud into a secondary position. Gradually, in the teaching, the printed material weakened the predominance of the oral transmission. From that point onwards, the learning method was no longer simply listening and writing down notes; the students could now manage their own studies on their own initiative.

As part of Enlightenment thinking, which prepared a new type of textbooks for public school systems, d'Alembert published in the Encyclopédie his important reflection on "elementarising" science. The advantages and disadvantages of the synthetic approach were also discussed (in line with Euclid's paradigm)m as was the analytical 
approach, which dominated shortly after the Revolution. D'Alembert also theorised on the learning process, criticising the prevalence of oral methods. He stated that one only masters what one learns for oneself, and he did not believe that the teacher carried out the fundamental work in the teaching process; rather students did because they were required to reflect and work hard ("méditation et travail"). Furthermore, D'Alembert criticised Clairaut's approaches as being unsuited for textbooks (Schubring 2003).

\section{$19^{\text {th }}$ century: The slow rise of algebra in secondary education}

The $19^{\text {th }}$ century witnessed the constitution of algebra as an important subject in the secondary education curriculum. During this period, its borders with arithmetic and geometry were delimited. The end of the century witnessed an important transformation in the didactics of this topic, with an increased emphasis on exercises.

Algebra in secondary education in different countries. The 1789 French Revolution ended the feudal system and led to State-organised public education throughout the nation. As a result, the écoles centrales were established as first form of secondary schools in 1795, paving the way for the creation of the École Polytechique in Paris in 1794.

In the first public secondary education mathematics programmes after the Revolution in 1802, algebra was given an important place ( $2^{\text {ème }}$ and $1^{\text {ère }}$ classes) using Lacroix's books to solve $1^{\text {st }}$ and $2^{\text {nd }}$ degree equations, equation systems, operations involving algebraic expressions, proportions, sequences, logarithms, and the numerical resolution of equations. The textbook procedure organised in the Napoleonic period established the principle of a compulsory book for the entire country (Schubring 2005, pp. 72-80).

However, the importance of mathematics in secondary education began to be reduced from 1809 onwards and drastically since the Restoration in 1815 . By the mid- $19^{\text {th }}$ century in France, it occupied an extremely weak position in public education. Mathematics had a significant role in supplementary education only, especially for the students who wanted to apply for enrolment into the Polytechnic school (Schubring, 2005, pp. 16-17). For these students, Louis Pierre Marie Bourdon (1779-1854) wrote his Eléments d'Álgèbre, published in 1817, which was broadly used up until the end of the $19^{\text {th }}$ century. The author himself accepted the influence of Lacroix's book and his concern to cater for the programme in place in the École Polytechique in Paris.

In contrast, in Prussia, after a slow growth in the $18^{\text {th }}$ century, algebra took on a noticeably strong presence in the 1810 programme. Of the nine years for the Gymnasium curriculum, algebra had to begin in the third year with the theory of $1^{\text {st }}$ and $2^{\text {nd }}$ degree equations and continue in fourth year with quadratic equations, calculations with powers, powers of a binomial, logarithms, and elements of analytical geometry; in the fifth year algebraic equations and numerical solutions, analytical geometry in 2 and 3 dimensions, and conical sections; and in the seventh year $3^{\text {rd }}$ and $4^{\text {th }}$ degree equations (sixth, eighth and ninth year were devoted to other topics). Although this programme served as a guideline and was not officially prescribed, it documented the analytic approach and the strong role given to mathematics education, thereby triggering the birth of the profession of the secondary education mathematics teacher (Schubring $2005 \mathrm{p}$. 17). Prussia, from the moment of Napoleon's defeat (1814), adopted a policy that emphasised the role of the teacher, and consequently oral methods, along with the acceptance of the dual teaching/researching function (Schubring 2003, p. 129). A new kind of school book was produced by Johann Andreas Matthias (1761-1837), with successive reprints from 1813 onwards: a concise guide manual (Leifaden) for students, a methodological complement for teachers, and a collection of exercises (Auf- 
gabensammlung). Meanwhile, at the same time as the pool of well-trained professional teachers was increasing, methodological aids for the teacher disappeared. Working documents began to be formed by the Leiftaden-Aufgabensammlun pair, making the collections of exercises extremely popular (Schubring 2003, pp. 137-140).

In Brazil, the Real Colégio Militar in Rio de Janeiro, which began giving lessons in 1811 (for youths aged 15 and over), included a complete mathematics course with algebra. The Academy looked to the École Polytechique in Paris as its reference point, using the new textbooks by Lacroix and Legendre written to replace Bézout's textbooks (in this country, the algebras of Euler and Lacroix were published in 1811 and 1813, but only the second received larger use). According to Valente (1999), the first year of this course covered several topics, "sometimes being a mathematics course which would be given in secondary education that did not exist at the time in Brazil" (p. 94). Years later, in 1837, the Colégio Pedro II was created to serve as the secondary school model throughout Brazil. In its study plan, algebra was taught in the $6^{\text {th }}$ year, after three years of arithmetic and two of geometry. In secondary schooling, which prepared students to enter higher education (for Engineering, Law, and Medicine degrees), mathematics assumed a new role. It no longer represented a technical knowledge that was specific to the military schools, but it was integrated into the general school syllabus for those who wanted to attend higher education (Valente 1999, pp. 105-119).

In Portugal, the Real Colégio Militar, specifically geared towards the children of officers, had been in operation since 1803. This course, which was six years, first makes a reference to algebra as a subject in the $3^{\text {rd }}$ year, alongside arithmetic, geometry, and trigonometry. Upon the creation of the secondary schools by Passos Manuel in 1836, the subjects of arithmetic, algebra, geometry, and trigonometry were offered. It is pointed out that the depth at which algebra is treated in the following periods depended on successive reforms. In higher education, the new polytechnic schools created in Lisbon and Porto in 1837 included subjects like elementary algebra and transcendent algebra on their syllabi, which were prerequisites for the differential and integral calculus and mechanics courses (Carvalho 1986). In Spain, in the secondary education syllabus of 1857, the $4^{\text {th }}$ year was dedicated to arithmetic and algebra and the $5^{\text {th }}$ year to geometry and trigonometry (Sierra, González \& López 2007).

Reorganisation of the topics. A major change in the policy of admission into higher education (especially engineering courses) during the $18^{\text {th }}$ century increased the importance of algebra at the secondary school level. At the time, algebra was a fundamental prerequisite for the study of infinitesimal calculus, and ultimately occupied a central position in the final years of secondary school education. On the other hand, the introduction of algebra in secondary education was accompanied by a reorganisation of the topics of elementary mathematics. At the start, the arithmetic-geometry-algebra sequence was followed, aligning with the organisation of Bézout's course (1764-69) and as shown in the syllabus of initial studies of the Colégio Pedro II (in 1837). However, Lacroix's books (1797-1805) introduced a new arithmetic-algebra-geometry sequence, based on the idea that algebra is nothing more than universal arithmetic. This became the sequence adopted by the Colégio Pedro II from 1841 onwards. An identical phenomenon occurred in other countries, leading to an algebraic processing of certain aspects of geometry. Therefore, as an example, Pedro d'Alcântara Bellegarde's compendium (1807-1864), published in Brazil for use in the Escola de Arquitetos Medidores (1838), began with elements of arithmetic (operation with integers, fractions, decimals, and the rule of three), before moving on to algebra, with such topics as the extraction of roots and logarithms, which were previously treated in the arithmetic course only. Apostillas de Algebra, by Luiz Pedro Drago, published in 1868 and used in the Colégio Ped- 
ro II, included algebraic operations and $1^{\text {st }}$ and $2^{\text {nd }}$ degree equations in the first part, and ratios and proportions, sequences, and logarithms in the second part (Valente 1999, pp. 119-127).

Hence, an evolution took place for what was treated within the scope of each of two subjects (arithmetic and algebra), and with a progressive study of topics such as logarithms and sequences in arithmetic and algebra. But an even more important evolution happened with the way certain topics of arithmetic or geometry were gradually tackled using algebra. Aritmética by Luis Piere Marie Bourdon (1779-1854), published in France $\left(1^{\text {st }}\right.$ edition in $1820,20^{\text {th }}$ edition in 1872) and organised into two parts, exemplifies this important landmark. The first part was purely arithmetic and the second part used algebraic language dealing with general properties of numbers, powers and roots, ratios and proportions, sequences and logarithms. This approach was introduced in Brazil by Cristiano Benedito Ottoni (1811-1896) in books that were used from 1855 onwards (Valente 1999, pp. 150-168). However, this adjustment between arithmetic and algebra occurred at a slow pace. As such, João António Coqueiro's (1837-1910) arithmetic book, published in 1860, included algebraic elements (namely algebraic expressions, $1^{\text {st }}$ degree equations, and system of equations). In contrast, António Trajano's Arithmetic (1843-1921), which was extraordinarily popular $\left(1^{\text {st }}\right.$ edition in $1879,136^{\text {th }}$ edition in 1958)m did not make any use of algebra (Valente 1999, pp. 159-165).

New didactics. At the end of the $19^{\text {th }}$ century, a new didactics for algebra emerged. We mentioned earlier the appearance of collections of exercises in Prussia from the start of the century. In France, Joseph Louis François Bertrand's books (18221900) contained a summary and a set of exercises at the end of each section. In Brazil, Coqueiro's arithmetic book, published in 1860, was the first to include exercises with and without solutions at the end of the chapter. The Apostillas de algebra by Luiz Pedro Drago, published in 1868, was organised into sections (which included problems, definitions or rules to learn), with exercises at the end of each chapter (Valente, 1999, p. 167). In Portugal, the books published by José Adelino Serrasqueiro (1835-?) from 1869 onwards were heavily influenced by Joseph Louis François Bertrand (1822-1900); like the French author, they included exercises at the end of the different sections.

Two didactics began to coexist. On the one hand was the "didactics of the lesson" (the "lecture"), which would be used in the military schools and which became typical in the preparatory colleges for higher education. As Valente points out (1991), in these didactics "saying prevails over doing" (p. 173). The course was conducted in a purely oral-often dictated-form, whereby the students took notes. The education, both oral and written, was based on long explanations about how to carry out certain procedures. On the other hand, the "didactics of the exercise" began to take shape, starting in the school practice. Here the students were given a different role: facing directly up to the difficulties posed by the exercises, whose complexity would lead us today to call them "problems" (Valente 1999; Ponte, Salvado, Fraga, Santos, \& Mosquito 2007). The use of exercise solving was made much easier by the introduction of a new toolthe blackboard - introduced by Frères de Lessale. This made it possible to correct exercises in direct interaction with the students, giving rise to the practice of "calling a student to the blackboard". The didactics of the exercise progressively broadened its sphere of influence, also entering higher education. ${ }^{2}$ The two didactical approaches-the lesson-lecture and the exercise-are still being used today, usually in combined form (Valente 1999, pp.173-176).

\footnotetext{
${ }^{2}$ In Portugal in the $20^{\text {th }}$ century, the algebra classes of a university mathematics course continued to be split into "theoretical classes" (with explanations and examples) and "practical classes" (with exercises). Similar practices are followed in many secondary schools, especially in the more advanced years.
} 


\section{$20^{\text {th }}$ century: Apogee and decline of the teaching of algebra}

The teaching of algebra in the $20^{\text {th }}$ century, at the secondary school level, is split into three large periods: the first, where algebra was viewed above all as the theory of polynomial equations and as preparation for the subsequent study of infinitesimal calculus, playing a very important role in the syllabi; the second, which was marked by the modern mathematics movement, algebraic structures, and algebra, inspiring the approach to studying numbers and geometry; and the third, which was marked by great uncertainty about algebra's place in the curriculum. In fact, throughout the 1950s, a number of wide-ranging initiatives were carried out with the common aim of modifying the mathematics teaching syllabi in order to update the mathematical topics taught, as well as to introduce new curriculum reorganisations and new teaching methods (Moon 1986; NACOME 1975).

Algebra in secondary education in different countries. In the USA in 1894, the Committee of Ten established elementary algebra as an important part of the secondary school curriculum (Myers 1979). A statement on college entrance requirements presented to a meeting of mathematicians in 1899 summarises what was expected for the candidates' mastery of algebra:

(i) The arithmetical side of algebra, including problems with literal quantities;

(ii) The "equational" side of algebra, including word problems;

(iii) Algebraic translation, including skills attained in manipulating long and complex algebraic expressions; and

(iv) Topics such as exponents, surds, quadratic equations, solving equations by factoring, and making algebraic statements from problems given in words.

Most algebra textbooks began with a presentation of "literal" numbers, that is, algebraic expressions. Then the student worked on solving equations, usually presented through world problems. According to Hirstein, Weinzweig, Fey, and Travers (1980), from the start of the century until the 1950s, the introductory algebra course served two purposes:

(i) to prepare the student to use algebra to solve "practical problems"; and

(ii) to furnish them with the manipulation skills needed for higher studies.

In Brazil, Serrasqueiro's algebra was used in the Colégio Pedro II from 1891 until at least 1923. This book introduced into algebra teaching the elementary theory of the determinants and their application in solving $1^{\text {st }}$ degree equations (Valente 1999, p. 168). The importance of the Elementos de Álgebra by FIC ( $1^{\text {st }}$ edition at the end of the $19^{\text {th }}$ century and the virtually identical $10^{\text {th }}$ edition in 1950) is evident. This book included algebraic calculus, $1^{\text {st }}$ and $2^{\text {nd }}$ degree equations, sequences, logarithms, interest, likelihood, and (in the appendix) a graphical representation of $1^{\text {st }}$ and $2^{\text {nd }}$ degree equations, Newton's binomial, exponential equations, notions of series, and so on (Valente 1999, pp. 187-188). Euclides Roxo (1890-1950) introduced a new curriculum at the Colégio Pedro II in 1929 that drastically changed secondary school mathematics education in Brazil. With this reform, mathematics was taught at every grade and the separation between arithmetic, algebra, and geometry disappeared. These subjects were taught in an integrated way and the function concept was introduced very early in the curriculum. However, in a later reform in 1942, some separation between the subjects recurred and the study of functions was postponed to a later stage of the curriculum (Carvalho 2006).

It is interesting to note that in Spain, the 1934 Reform (which only lasted until the end of the civil war in 1939) introduced the "cyclical method". As such, the first course presented the initial notions of arithmetic and intuitive geometry, and the rec- 
ommendation was for more emphasis on an intuitive and practical approach. In the $3^{\text {rd }}$ and $4^{\text {th }}$ years, the same concepts were tackled, but this time through a "rational presentation". In subsequent years, real numbers, limits and continuity of functions and topics such as logarithms, arithmetic and geometric sequences, and complex numbers were studied (Sierra, González \& López 2007). Some topics began to the taught earlier, such as the $2^{\text {nd }}$ degree equation that moved from the $5^{\text {th }}$ to the $4^{\text {th }}$ year.

Mathematics as a unified subject? Finally, another question that marked the $20^{\text {th }}$ century, in terms of the secondary school mathematics curriculum, was the issue of whether it must be organised into separate sub-subjects or if mathematics must be presented as an integrated single subject. As early as 1903 in the USA, Eliakim Hastings Moore (1862-1932) called for a curriculum where the different branches of mathematics would be unified (Kilpatrick 1992); later, the Bourbakist movement made the issue of the unity of mathematics one of its central themes.

An important moment in this discussion was the CIEM meeting in 1911 in Milan, which intended to "pursue the study of current trends in mathematics education" with special attention on the "the issue of merging the different branches of mathematics" (CIEM circ 4, EM13 1911, pp. 122-123). The account of the discussion (EM 13, p. 468-471) makes a distinction between "purist" and "fusionist" trends. The former separates the various areas of mathematics in a strict way, while the latter does not make this separation but rather creates some kind of "integration" between different branches of mathematics. In the presentation of a given branch of mathematics, the "fusionists" use examples or representations of another branch: for example, "graphical representations in arithmetic or algebra," "trigonometry formulas in geometry," and geometrical examples in the theory of proportions (EM 13, pp. 468-469). The account of this meeting indicates that "the fusion of subjects can be made in very different levels of depth" and notes that there was a large variation among different countries to this respect among syllabi and methods (EM 13, p. 469). The discussion mainly addressed aspects related to the teaching of geometry, but noted that "there is fusion in most countries" between algebra, or arithmetic, and geometry (one exception were the Italian lyceums). The most important highlight of this "fusion" was the very frequent use of graphical representations and the teaching of "one year" of analytic geometry in countries such as Austria and Switzerland (EM 13, p. 469).

Despite this discussion, Carvalho (2006) indicates that in Brazil, in the 1920s, the subjects of secondary school mathematics (arithmetic, algebra, geometry, and trigonometry) were still taught in a strictly compartmentalised way, separated by school years. However, an increasing number of mathematics study plans integrating the different topics, especially algebra and geometry, began to appear in many countries. For example, in Spain, as a result of the 1934 Reform, mathematics was presented in a unified manner, eliminating the separation into disconnected subjects. Curiously, one of the few countries in the world where this integration did not yet occur was the USA, where most of the schools continued to have an algebra course in the $9^{\text {th }}$ grade followed by a geometry course in the $10^{\text {th }}$ grade.

Approach centred on equations or on functions? According to Artigue, Assude, Grugeon and Lenfant (2001), in France in the $20^{\text {th }}$ century, until modern mathematics, algebra was an essential topic on the curriculum, alongside arithmetic and geometry, whereby its central concept was the equation. This trend also occurred in most countries, although in some cases through an extremely abstract approach which was essentially backed up by work with algebraic expressions (with one or various variables) and in other cases with a significant emphasis on word problems. 
In the early $20^{\text {th }}$ century in Germany, Felix Klein (1849-1925) suggested that the concept of function should occupy a central position throughout the entire secondary education curriculum, and thus the teaching of algebra should be changed. Klein's proposal became one of the most keenly debated issues in the initial phase of the ICMI. The role of the concept of function and its importance and relationship with the concepts of traditional algebra were discussed. This perspective pleased those who valued the applications, given that the concept of function is an important modelling tool. It also pleased many who were concerned about the learning of differential and integral calculus, where the concept of function plays a central role. In contrast, it did not please those who considered the learning of algebraic manipulation (expressions and equations) as the fundamental basis for the subsequent studies of mathematics. The fact is that this idea generated an important international movement of curriculum development, leading Kilpatrick (1992) to say that "the banner for the reform of secondary school mathematics would be the concept of function" (p. 7). By the mid $20^{\text {th }}$ century, Klein's ideas had won a half victory-the concept of function occupied a central position in the syllabus of the final phase of this teaching level (grades 10-11), but it had a very small role in the initial phase (grades 7-9).

Evolution of the treatment of algebraic topics. Along with the evolution of the role of the concept of function, we witnessed throughout the $20^{\text {th }}$ century a significant evolution in the treatment of algebraic topics. Some progressively lost importance and even disappeared from syllabus (such as solving $3^{\text {rd }}$ degree equations, solving systems of three or more equations, determinants, solving equations involving algebraic fractions and irrational expressions, series and Newton's binomial). Furthermore, the approach to central concepts also changed. For example, in Portugal between the end of the $19^{\text {th }}$ century and the end of the $20^{\text {th }}$ century, the teaching of the $1^{\text {st }}$ degree equation was carried out earlier and in a more simplified manner. Initially, algebraic expressions were studied in a single year (including algebraic fractions), along with numerical and literal equations, and finally systems of equations. Later, separate stages of this area of study were differentiated, with each topic studied in different years. Algebraic expressions were no longer treated as before, as a prerequisite for equations; instead, they were introduced based on the actual study of equations in an attempt to motivate the study of this topic, which was acknowledged as being arduous and uninteresting (Ponte, 2004).

The role of applications in mathematics teaching is a subject of debate during the entire $20^{\text {th }}$ century. Both equations and functions are concepts that have many applications both outside and inside mathematics. In England, John Perry developed a new curriculum on practical mathematics and argued for a more intuitive and laboratorybased approach in a 1901 address. Klein, as we have seen, was also in favour of an emphasis on the applications of mathematics. Despite this, the approach that prevailed in most countries placed applications in a secondary position (Carvalho 2006).

The modern mathematics movement. At the end of the $19^{\text {th }}$ century, algebra changed its focus as a field of research. It no longer focused foremost on the study of polynomial functions, but centred on the study of structures, starting with group structure. The influence of the Modern Algebra textbook written by Bartelt van der Waerden (1903-1996), published in 1930-31, represented a revolution not only in algebra teaching, but also in algebra research. The Bourbakist movement became the visible face of a programme that placed algebra as the integrating part of mathematics and which would have a large influence on the curriculum movement of modern mathematics.

In the USA, initially the changes were cautious, as we can see in the 1959 recommendations report by the Commission on Mathematics of the CEEB (College Entrance Examination Board): 
The recommendations of the CM do not envisage changes in the mechanics of formal manipulations of algebra. They will be the same as hitherto taught, and the subject matter will be largely the same. The differences will be in the concept, in terminology, in the symbolism, in graphs on the line, and in the inclusion of a rather new segment of new work dealing with inequalities. There will be a shift in emphasis from mechanical manipulations to the development of concepts, which is equally important. Of course, the development of adequate skills continues to be an important objective of the high school algebra course. (Hirstein, Weinzweig, Fey, \& Travers, 1980, p. 377)

In 1959, the Organisation for Economic Cooperation (OEEC) decided to hold a working session aimed at promoting a deep-rooted reform in the teaching of this subject. This work session took place at the Cercle Culturel de Royaumont in France, lasting two weeks and gathering around fifty delegates from eighteen countries (OEEC 1961a). It came up with general guidelines for a proposal to reform mathematics education, heavily influenced by the dominant structural ideas of the time, particularly with regard to mathematics and psychology; the most ardent advocate was Jean Dieudonné. This proposal was specified a year later, in Dubrovnik, with the writing of the book Synopses for modern secondary school mathematics (OEEC 1961b).

Two main guidelines stand out in Royaumont's proposal (OEEC, 1961a) with regard to the content and curriculum organisation for a new mathematics programme: on the one hand, it gave emphasis to the unity of mathematics; on the other, it introduced new topics and approaches of mathematics, labelled modern. These recommendations above all empowered algebra and vector geometry and placed a correspondingly lesser value to Euclid's geometry, in the axiomatic orientation given to the study of mathematics whereby the mathematical language and symbolism are emphasised.

Algebra appears in the programmatic recommendations of Royaumont as a unifying item par excellence. An example of this is Choquet's proposal (OEEC 1961a) for the teaching of arithmetic; he argued for the merging of arithmetic and algebra, which he believed was possible based on the study of mathematical structures. Other examples are those suggested by an algebraic approach to geometry, which is in line with the proposal to begin its study with geometric transformations "starting with translations, rotations and reflections and proceeding step by step to a more generalised application of groups of transformations" (OEEC 1961a, p. 77), as well as recommendations for teaching vector geometry as early as possible at school, in order to synthesize algebra and geometry.

Also relative to the emphasis on algebra in education, Servais (OEEC 1961a) argued that presenting its study as a simple generalised extension of arithmetic gives a distorted vision of that domain of mathematics. Therefore, he stated, algebra should not be restricted to the numerical field immediately at the inception of its study in the secondary schools. Hence, he made his proposal for the early introduction of algebra with sets, justified by the fact that with the use of sets "from the start the field of algebra is not confined to the algebra of numerical operations" (OECE 1961a, p. 69). Servais proposed the study of set theory and argued that sets should become familiar to students as early as possible. He suggested that the notion of function should be introduced based on this theory and directly from the beginning of school. According to Servais, with the preliminary study of the notions of set, function, Cartesian product, relations, and operations, "algebra would be given the role in mathematics which it is increasingly acknowledged, it deserves" (OEEC 1961a, p. 71). 
In tandem with the prominence of algebra, vector geometry was adopted which led to an accordingly lower emphasis on Euclid's geometry. Dieudonné (OEECa 1961) played a leading role in this shift. In his famous statement, which he himself accepted as encapsulating his ideas, he argued: "If the whole programme I have in mind had to be summarised in one slogan it would be: Euclid must go!" (p. 35). In truth, Dieudonné was extremely critical about the teaching of geometry that was practised at the time, proposing that it should be completely replaced by transformational geometry and vector geometry. As such, algebra also penetrated geometry, as was stated in the final conclusions of the seminar: "a more thorough and effective treatment of logical aspects of these subjects is imperative (...) and this adaptation further demands the earliest possible exposition of the connections between geometry and algebra-particularly linear and vector algebra" (OEEC 1961a, p. 122).

The programme drawn up by Dubrovnik (OECE 1961b) incorporated many of Royaumont's guidelines and proposals. The two main topics were precisely algebra and geometry, spread over two cycles-11-15 years and 15-18 years-whereby in this last topic, the programme proposed an algebraic approach with the systematic study of geometric transformations, first introducing the notions of vector, angle, and symmetry (and reflection), then studying other transformations (OECE, 1961b). For the first cycle (11-15 years), algebra started with set theory, from elementary notions of the theory to the study of properties, relations, and operations with sets, including notions of binary relation, Cartesian product of two sets, and function and mapping of sets. Despite the disagreements expressed in Royaumont, Dubrovnik's programme included the study of these structures right at the outset of the first $1^{\text {st }}$ cycle, considering that " $[\mathrm{t}]$ here is no intention of introducing, at this level, a systematic or formal study of rings and fields" (OECE 1961b, p. 81). In the second cycle (15-18 years), algebra deepened set theory and prolonged until linear spaces, linear applications, and matrices.

Hence, regarding the modern mathematics period, we can talk about a structural approach (emphasis on the structures) as well as a functional approach (emphasis on the concept of function). In addition to introducing specific topics (such as elements of set theory and the study of abstract algebraic structures such as group, field and linear space), it began to inspire all the work in arithmetic and geometry. While in preceding periods, the study of the $1^{\text {st }}$ degree equations was based on the principles of equivalence, presented formally (as theorems) or as practical rules, in this period another practice was put into place, initially seeking to solve equations based on the definition of numerical operations and their properties. Only later were guidelines presented and practical rules formulated for solving equations (Ponte 2004).

The post-reform period. Modern mathematics represents the overwhelming triumph of algebra, but it was a short-lived triumph. In the following period, there was a sizable reduction in topics of an algebraic nature in the curriculum, and a substantial simplification of symbolism. Functions were dealt with separately and, at the elementary level, at times in association with statistics. In several countries such as France and Portugal, although many algebra topics continued to be covered at various points in the curricula, they disappeared as separate topics. In France, the emphasis was put on modelling; in Portugal, algebra was regarded only as computation (operations with expressions, solving equations, inequalities, and systems), and functions were taught as a different topic (Artigue, Assude, Grugeon, \& Lenfant 2001; Ponte 2006). Artigue, Assude, Grugeon, and Lenfant (2001) believe that today several trends live alongside one another, which they label empirical (emphasising modelling), structural (emphasising structures), and centred on equations (the "classic" approach). 
In the 1990s in the USA, a new trend emerged that gave algebra a prominent role in the school syllabus; this was supported by the NCTM (2000), making algebra a curriculum strand from the start of primary school. This movement, which has had visible impact on the curriculum in several countries, was underpinned by the central idea of "development of algebraic thinking" which focused on the notions of generalisation and symbolisation, valuing the work with sequences, a functional approach to proportion, and the structural properties of the number sets.

\section{Conclusion: What is the outlook for algebra in education?}

The history of algebra education set forth here in general terms gives rise to several reflections, with which we end the chapter. First, we need to consider the technologies available in each epoch, which clearly had a decisive role in the way algebra was taught over time. The difficulty in carrying out and reproducing written records led to the lengthy predominance of oral education. The emergence of print enabled the intensive use of written material, which then was considered and presented as a superior alternative to oral methods. Later, the oral/written dichotomy became a combination of oral and written teaching, with variations to a greater or lesser degree depending on local traditions. Today, we are in a period of rapid development of new digital technologies (internet, web 2.0, interactive boards), which will certainly heavily influence mathematics teaching, in particular the teaching of algebra, although its direction is not yet known (Moreno-Armella, Hegedus \& Kaput 2008).

A second reflection is linked to approaches to algebra education, and especially to the tasks used. Verbal problems played an important role in algebra education until well into the $20^{\text {th }}$ century. From a certain time, algebra began to constitute, in itself, a wealth of problems, giving rise to two large didactic movements-one following a purer mathematics line using problems formulated solely in mathematical terms, the other profusely using word problems within the scope of extra-mathematical contexts. Upon the consolidation of the concept of function as the central idea of algebra teaching, a third kind of task has progressively gained predominance - tasks involving modelling of real situations. One can argue, like Puig (2004), that students' difficulties in word problems are linked to the lack of teaching this topic, meaning that they cannot understand the logic underlying the Cartesian method. But in truth, it is very difficult to give a central role to word problems without making them artificial, especially when moving into a more advanced study of algebra. On the other hand, it is possible that the issue of tasks is not restricted to finding the key task that can serve as the basis of all education, but rather the combination of different kinds of tasks that provide the experiences needed to bring about desired learning.

Other issues pertaining to the approach to follow underwent successive inflections throughout history, such as the role of explanations versus the role of problems, the role of the teacher and the role of the student, the synthetical approach versus the analytical approach, the relationship of algebra with other fields outside and inside mathematics, and the role given to symbolism and the problem of abstraction, which began as notable progress until it became an obstacle to learning for most students. The fact is students who study algebra change from epoch to epoch, much like their motivations and the conditions in which they study also change. A successful approach in a given epoch with a given group of students may prove disastrous in another epoch and with other students.

Finally, we see how, over time, the presence of algebra in secondary school syllabi has evolved greatly. As such, algebra has moved through progressive affirmation in the mathematics curriculum, reaching dominance in the first half of the $20^{\text {th }}$ century. 
Afterwards, with Modern Mathematics, algebra was given an absolutely hegemonic position, virtually inspiring the whole curriculum at this level. Not only did algebra occupy a prominent role, but the approach to numbers and geometry was undertaken from an algebraic perspective, in line with its respective structures. However, in the subsequent period, the role of algebra was questioned drastically, losing visibility as an independent topic, and becoming a simple residue, with algebraic computation as a prerequisite for the study of infinitesimal calculus and a modicum of algebraic structures serving as glue for different topics. It will be interesting to see to what extent current-day conceptualisations about algebraic thinking, early algebraic thinking, and new modelling-based approaches are able to guarantee a stable and lasting place for algebra on the school curriculum and to what degree they contribute to the success of students' learning in mathematics.

\section{References}

Artigue, Michèle, Assude, Teresa, Grugeon, Brigitte, \& Lenfant, Agnès (2001). Teaching and learning algebra: Approaching complexity through complementary perspectives. In Helen Chick, Kaye Stacey, Jill Vincent \& John Vincent (Eds.), The future of the teaching and the learning of algebra (Proceedings of the 12th ICMI Study) (pp. 21--32). Melbourne: The University of Melbourne.

Boyer, Carl B., \& Merzbach, Uta C. (1980). A history of mathematics. New York, NY: Wiley.

Carvalho, João P. (2006). A turning point in secondary school mathematics in Brazil: Euclides Roxo and the mathematics curricular reforms of 1931 and 1942. The International Journal for the History of Mathematics Education, 1(1).

Carvalho, Rómulo (1986). História do ensino em Portugal. Lisboa: Fundação Calouste Gulbenkian.

Dunham, William (2000). Euler: El maestro de todos los matemáticos. Madrid: Nivola.

Fletcher, Trevor J. (1980). Algebra in English secondary schools: Changes over twenty years. In H.-G. Steiner (Ed.), Comparative studies of mathematics curricula: Change and stability 1960-1980 (pp. 354-369). Bielelfeld: IDM.

Hawking, Stephen (2010). Dios creó los números: Los descubrimentos matemáticos que cambiaron la historia. Barcelona: Crítica.

Hirstein, James J., Weinzweig, Avrum. I., Fey, James T., \& Travers, Kenneth J. (1980). Elementary algebra in the United States: 1955-1980. In H.-G. Steiner (Ed.), Comparative studies of mathematics curricula: Change and stability 1960-1980 (pp. 370-394). Bielelfeld: IDM.

Hyrup, Jens (2002). Lengths, widths, surfaces: A portrait of old Babylonian algebra and its kin. New York, NY: Springer.

Kilpatrick, Jeremy (1992). A history of research in mathematics education. In D. A. Grouws (Ed.), Handbook of research on mathematics teaching and learning (pp. 3-38). New York: Macmillan.

Moon, Bob (1986). The 'new maths' curriculum controversy: An international story. Londres: Falmer. 
Moreno-Armella, Luis, Hegedus, Stephan, \& Kaput, James J. (2008). From static to dynamic mathematics: historical and representational perspectives. Educational Studies in Mathematics, 68, 99-111.

Myers, Shirley P. (1979). Changes in the content sequence of elementary algebra from 1894 to 1977. Dissertation Abstracts International, 39, 7206-A.

NACOME (1975). Overview and analysis of school mathematics: Grades k-12. Reston, VA: NCTM.

OEEC (1961a). New thinking in school mathematics. Paris: Organization for European Economic Cooperation.

OEEC (1961a). Synopses for modern secondary school mathematics, Paris: Organization for European Economic Cooperation.

Ponte, João-Pedro (2004). As equações nos manuais escolares. Revista Brasileira de História da Matemática, 4(8), 149-170.

Ponte, João-Pedro (2006). Números e álgebra no currículo escolar. In Isabel Vale, Teresa Pimentel, Ana Barbosa, Lina Fonseca, Leonor Santos \& Paula Canavarro (Eds.), Números e álgebra na aprendizagem da Matemática e na formação de professores (pp. 5-27). Lisboa: SEM-SPCE.

Ponte, João-Pedro, Salvado, Carmen, Fraga, Ana, Santos, Teresa, \& Mosquito, Elisa (2007). Equações do 2. ${ }^{\circ}$ grau do fim do século XIX ao início do século XXI: Uma análise de sete manuais escolares. Quadrante, 16(1), 111-145.

Puig, Luis (2004 July 4-11). History of algebraic ideas and research on educational algebra. Regular Lecture at ICME-10. Copenhagen (Text available at: http://www.uv.es/puigl/).

Schubring, Gert (2003). Análise histórica de livros de Matemática. Campinas: Autores Associados.

Schubring, Gert (2005). Pesquisar sobre a história do ensino da Matemática: Metodologia, abordagens e perspectivas. In Darlinda Moreira \& José Manuel Matos (Eds.), História do Ensino da Matemática em Portugal (pp. 5-20). Lisboa: SPCE.

Sierra-Vázquez, Modesto, González-Astudillo, María T., \& López-Esteban, María (2007). Estudio de evaluación de las Matemáticas en Castilla y León: Junta de Castilla y León.

Teixeira, Francisco G. (1934). História das Matemáticas em Portugal. Lisboa: Academia das Ciências.

Valente, Wagner R. (1999). Uma história da matemática escolar no Brasil (17301930). São Paulo: Annablume. 